\title{
Association Between Low Vitamin D Levels and the Greater Impact of Fibromyalgia
}

\author{
Susyane Ribeiro Beserra ${ }^{\mathrm{a}, \mathrm{c}}$, Fabiola Isabel Suano Souza ${ }^{\mathrm{a}}$, Roseli Oselka Saccardo Sarni ${ }^{\mathrm{a}}$, \\ Myllena Maria de Morais Pereira ${ }^{b}$
}

\begin{abstract}
Background: Fibromyalgia (FM) is a clinical syndrome mainly characterized by generalized chronic pain, fatigue, sleep and cognition disorders. The role played by vitamin D in the pathophysiology of painful syndromes is poorly known. Studies assessing the association between vitamin D and FM have presented conflicting results. The aims of the current study were to assess vitamin D levels in FM patients, by comparing them to healthy controls, as well as to analyze their impact on this disease.
\end{abstract}

Methods: This was a cross-sectional study comprising 43 FM patients (ACR 2010 criteria) and 40 healthy individuals. All participants had their vitamin D levels measured, and FM patients also had their total calcium, albumin, phosphorus and parathyroid hormone (PTH) measured. Clinical variables capable of affecting the results were evaluated and the fibromyalgia impact questionnaire (FIQ) was applied.

Results: There was not statistically significant difference in global mean values of vitamin D between groups. In the total sample, only $4.8 \%$ of the individuals had vitamin D deficiency, which corresponded to the deficiency found in the group of patients; in the control, no one had vitamin deficiency; $39.8 \%$ had insufficient levels and $55.4 \%$ with sufficient levels. The mean serum vitamin $\mathrm{D}$ values were similar between the FM and control groups $(34.8 \pm 12$ and $34.7 \pm 12.3 \mathrm{ng} /$ $\mathrm{mL}$, respectively; $\mathrm{P}=0.806$ ). However, a significant negative correlation was found between vitamin D concentration and FIQ values, that is, patients with the greatest impact of the disease had lower concentrations of vitamin $\mathrm{D}(\mathrm{P}=0.018)$.

Conclusion: FM patients did not present higher prevalence of vitamin $\mathrm{D}$ deficiency or insufficiency than healthy individuals, although low

Manuscript submitted May 19, 2020, accepted June 12, 2020

Published online June 25, 2020

${ }^{a}$ Centro Universitario Saude ABC, Av. Principe de Gales, 821, Principe de Gales, CEP: 09060-650, Santo Andre - SP, Brazil

bUniversidade Federal do Cariri, UFCA/Campus Barbalha, R. Divino Salvador, 284, Rosario, CEP: 63180-000, Barbalha - CE, Brazil

${ }^{\mathrm{c} C o r r e s p o n d i n g ~ A u t h o r: ~ S u s y a n e ~ R i b e i r o ~ B e s e r r a, ~ F a c u l d a d e ~ d e ~ M e d i c i n a ~ d o ~}$ ABC, Av. Principe de Gales, 821, Principe de Gales, CEP: 09060-650, Santo Andre - SP, Brazil. Email: srbeserra@gmail.com

doi: https://doi.org/10.14740/jocmr4136 vitamin D concentrations could indicate more severe disease impacts.

Keywords: Vitamin D; Fibromyalgia; Chronic pain; Fibromyalgia impact

\section{Introduction}

Fibromyalgia (FM) is a clinical rheumatic condition characterized by chronic diffuse musculoskeletal pain associated with nonspecific symptoms such as fatigue, sleep and mood disorders, as well as with cognitive disorders such as poor concentration and memory $[1,2]$. The disease is more often diagnosed in individuals in the age group of 35 - 60 years, but it can also affect younger and elderly individuals. The prevalence of FM in Brazil reaches up to $2.5 \%$, and it is more often diagnosed in women [3].

FM is a multifactorial disease that changes central nociceptive pathways such as serotonin, dopamine and catecholamine. There is no evidence that a single event is responsible for FM development; many physical and/or emotional stressors can trigger or worsen its symptoms. The disease causes generalized pain, which affects the quality of life and leads to functional limitation in affected individuals [4].

Nowadays, it is well known that vitamin D is more than an essential nutrient (prohormone) to several tissues, as well as that it is involved in a whole range of biological systems rather than just limited to bone metabolism [5]. Vitamin D deficiency is not only associated with musculoskeletal disorders such as higher fracture rates, lower limb motor dysfunctions, osteomalacia and pain; it also acts in the pathogenesis and progression of several extra-skeletal disorders [6].

According to the literature, vitamin D plays a controversial role in FM pathophysiology [7]. Scientific studies are inconclusive about the relationship between FM and vitamin D concentrations, which makes it hard to suggest investigating or supplementing this vitamin [8]. Only two studies about the association between FM and vitamin D were published in Brazil $[9,10]$; therefore, investigating this link is of great scientific importance given the potential negative impact of FM on patients' quality of life, and the hypothesis that vitamin D deficiency is a triggering or worsening factor of the disease. The current study had compared serum vitamin D concentrations measured in Brazilian FM patients (Northeastern region) 
to those of healthy controls, as well as investigated the possible association between such concentrations and the impacts of the disease.

\section{Materials and Methods}

The study included FM patients in the age group of $18-60$ years, who met the FM criteria set by the American College of Rheumatology (ACR) [2]. The adopted convenience sample comprised patients treated at the Outpatient Clinic of Joao Pereira dos Santos Rheumatology Polyclinic in Barbalha County, Ceara State, Northeastern Brazil. Participating in the study were patients who met the criteria of the ACR (2010) for FM, aged between 18 and 60 years. The survey also included a control group of healthy and eutrophic volunteers from the same region, matched by gender and age. Individuals from both groups were excluded if they were using vitamin $\mathrm{D}$, or who had comorbidities that interfered with vitamin D absorption and metabolism, such as kidney or liver failure, malabsorption syndromes, inflammatory bowel disease, use of anticonvulsants, tuberculostatic drugs, in addition to pregnant and lactating women and diagnosed with other rheumatological diseases.

The geographical region where participants live in is located at latitude $7^{\circ}$ South and longitude $39^{\circ}$ West. The climate in this region is semi-humid, it does not present sudden temperature fluctuations, its mean temperature is $25^{\circ} \mathrm{C}$ - temperature is lower in June and July. The region has approximately 12 $\mathrm{h}$ of sunlight throughout the day $[11,12]$.

The study followed a cross-sectional and controlled design. Participants were subjected to clinical evaluation, which was based on a questionnaire applied to collect sociodemographic data such as sex, age, skin color, disease characteristics, medications currently in use and lifestyle (exercising, sedentariness, smoking habit, alcohol consumption). Sunlight exposure and skin type were also investigated to complete the fibromyalgia impact questionnaire (FIQ), which comprised questions organized in 10 different items focused on investigating about participants' functional capacity, professional status, psychological disorders and physical symptoms. The greater the impact of the disease, the higher the score found [13]. Pain was assessed through the visual analogue scale (VAS). Participants' weight and height were measured in order to assess their nutritional status based on the body mass index formula: BMI $=\mathrm{kg} / \mathrm{m}^{2}[14]$; these values were classified based on recommendations by the World Health Organization [15]. The control group comprised healthy individuals whose information was collected from the database of a clinical research carried out concurrently. Individuals in the control group were assessed based on age, sex, exercising or sedentariness, sunlight exposure, skin type and vitamin D concentrations, but they were not evaluated based on the time they spent at home.

Data about FM patients and control individuals were collected from February to August 2016; this time-period corresponds to the summer, autumn and winter seasons. Participants were asked whether they were exposed to sunlight for at least half an hour per day, or at least 3 - $4 \mathrm{~h}$ per week, and whether they remained indoors most of the time. Skin phototype evalu- ation was based on the Fitzpatrick scale, which indicates skin tolerance to ultraviolet light based on patients' report about sunburn and tanning [16]: I (white, always gets burned when exposed to sun, never tans, very sensitive to the sun), II (white, always gets burned when exposed to sun, tans minimally, sensitive to the sun), III (light brown, burns moderately when exposed to sun, tans moderately, normal sensitivity to the sun), IV (moderate brown, burns minimally when exposed to sun, always tans, normal sensitivity to the sun), V (dark brown, rarely burns when exposed to sun, always tans, little sensitive to the sun), VI (black, never burns when exposed to sun, totally pigmented, not sensitive to the sun).

The quantitative 25-OH-D determination method is a direct competitive test based on the chemiluminescence immunoassay (CLIA) principle [17]; the herein used Beckman Coulter kit was measured in DXI 800 equipment. Vitamin D values were classified as deficient $(\leq 20 \mathrm{ng} / \mathrm{mL})$, insufficient (21 to $30 \mathrm{ng} / \mathrm{mL}$ ) and sufficient (31 to $60 \mathrm{ng} / \mathrm{mL}$ ) [18]. The following bone metabolism markers were measured in the group of patients: total calcium, albumin, phosphorus (colorimetric method) and parathyroid hormone (chemiluminescence method).

Data were analyzed in the IBM SPSS software version 23.0. Absolute and relative frequencies were calculated for qualitative variables, whereas mean and standard deviation were calculated for quantitative variables. The normality of the list of vitamin D measurements was assessed through Shapiro-Wilk test; results did not show significant values $(\mathrm{P}=$ 0.008), which indicated non-normality. Correlations were expressed through Spearman's correlation coefficient. Given data non-normality, Mann-Whitney, Kruskal-Wallis and Spearman correlation significance tests were applied to investigate the association between variables. Qualitative variables were subjected to Fisher's exact test. All inferential procedures adopted significance level of $5 \%$.

The research was in compliance with the ethical aspects of human research and it was approved by the ethics committee of the ABC School of Medicine/ABC-FMABC Foundation, under number 50543115.4.0000.0082.

\section{Results}

Eighty-three (83) individuals participated in the study: $43 \mathrm{FM}$ patients and 40 healthy controls, 81 women and two men (one in each group). Three FM patients and four controls reported having high blood pressure and using antihypertensive drugs; approximately $30 \%$ of FM patients were on antidepressants. Most FM patients $(60.5 \%)$ reported being exposed to sunlight for at least half an hour a day, or at least 3 - $4 \mathrm{~h}$ a week, although they stay at home most of the time (Table 1). FM patients exposed to the sun presented significantly higher vitamin D concentrations than the non-exposed ones (Table 2).

With respect to skin phototype, $48.9 \%$ of patients presented type III, $20.9 \%$ presented type II and $11.6 \%$ presented type $\mathrm{V}$; phototypes I and IV recorded the lowest rate $(9.3 \%)$, and no one presented phototype VI (Table 1). Phototype IV individuals presented the highest vitamin D concentration $(39.8 \mu \mathrm{g} / \mathrm{mL}$, on average) and they were followed by phototype I individu- 
Table 1. FM Patients' Featuring (Qualitative Variables)

\begin{tabular}{|c|c|c|}
\hline Variables & $\mathbf{n}$ & Percentage \\
\hline \multicolumn{3}{|l|}{ Age group } \\
\hline 23 to 30 years & 3 & 7.0 \\
\hline 31 to 40 years & 14 & 32.6 \\
\hline 41 to 50 years & 11 & 25.6 \\
\hline 51 to 60 years & 15 & 34.8 \\
\hline \multicolumn{3}{|l|}{ Skin phototype } \\
\hline I & 4 & 9.3 \\
\hline II & 9 & 20.9 \\
\hline III & 21 & 48.9 \\
\hline IV & 4 & 9.3 \\
\hline V & 5 & 11.6 \\
\hline \multicolumn{3}{|l|}{ Smoking } \\
\hline Yes & 7 & 16.3 \\
\hline No & 36 & 83.7 \\
\hline \multicolumn{3}{|l|}{ Alcohol consumption } \\
\hline Yes & 3 & 7.0 \\
\hline No & 40 & 93.0 \\
\hline \multicolumn{3}{|l|}{ Exercising } \\
\hline Yes & 15 & 34.9 \\
\hline No & 28 & 65.1 \\
\hline \multicolumn{3}{|c|}{ Exposure to the sunlight ${ }^{\mathrm{a}}$} \\
\hline Yes & 26 & 60.4 \\
\hline No & 15 & 34.9 \\
\hline No information & 2 & 4.7 \\
\hline \multicolumn{3}{|l|}{ Indoors $^{\mathrm{b}}$} \\
\hline Yes & 27 & 62.7 \\
\hline No & 14 & 32.6 \\
\hline No information & 2 & 4.7 \\
\hline
\end{tabular}

aExposure to sunlight for at least half an hour a day, or at least $3-4 \mathrm{~h}$ a week. ' Staying indoors most of the days. FM: fibromyalgia.

als $(38.1 \mu \mathrm{g} / \mathrm{mL})$; phototype $\mathrm{V}$ individuals presented the lowest vitamin $\mathrm{D}$ concentration. There was statistically significant difference in skin phototype between FM patients and controls ( $\mathrm{P}$ $=0.023)$ (Table 3$)$.

All FM patients presented moderate-to-severe pain based on the VAS; $76.7 \%$ of them presented severe pain and $23.3 \%$ had moderate pain. In total, $45.4 \%$ of patients with severe pain recorded vitamin D levels lower than $30 \mathrm{ng} / \mathrm{mL}$, whereas only $9 \%$ of them recorded values lower than $20 \mathrm{ng} / \mathrm{mL}$; there was not statistically significant difference between these patients. The negative correlation between vitamin D concentration and FIQ values was significantly weak, i.e., patients presenting stronger disease impact had low vitamin D concentrations (Table 4).

Table 3 presents the global mean vitamin D levels and their classification as deficient, insufficient and sufficient. There was not statistically significant difference in global mean values of vitamin D between groups. Only $4.8 \%$ of FM patients presented vitamin $\mathrm{D}$ deficiency, whereas the control group did not present such deficiency; $39.8 \%$ of FM patients had insufficient vitamin $\mathrm{D}$ levels and $55.4 \%$ of them presented sufficient levels of it. No patient presented severe vitamin D deficiency $(<10 \mu \mathrm{g} / \mathrm{mL})$.

This study conforms to STROBE statement (Strengthening the Reporting of Observational Studies in Epidemiology) [19].

\section{Discussion}

The cutoff point adopted for 25-OH-D concentrations was the one recommended in the 2011 Endocrine Society (ES) Guideline, according to which, individuals can be classified as vitamin $\mathrm{D}$ deficient (values lower than $20 \mathrm{ng} / \mathrm{mL}$ ), insufficient (values equal to or higher than $20 \mathrm{ng} / \mathrm{mL}$ and lower than $30 \mathrm{ng} /$ $\mathrm{mL}$ ) and sufficient (values equal to or higher than $30 \mathrm{ng} / \mathrm{mL}$ up to $100 \mathrm{ng} / \mathrm{mL}$ ) [18].

The association between vitamin D levels and FM syndrome, whether there is association between hypovitaminosis $\mathrm{D}$ and FM, is conflicting in the literature. Armstrong et al [20] evaluated vitamin D levels in 75 FM patients; their results showed that $13.3 \%$ of patients were vitamin D deficient, $56 \%$ were vitamin D insufficient and $30.7 \%$ had normal vitamin D levels; however, there was no correlation between vitamin D levels and FIQ. Okyay et al [21] analyzed vitamin D levels and biochemical markers in 79 women with FM syndrome and in 80 healthy women; their results showed serum vitamin D levels lower in FM patients than in healthy controls. Vitamin D level was significantly and negatively correlated to VAS, tender point count and FIQ [21]; however, this association was not observed in other studies $[22,23]$.

The study conducted by de Rezende Pena et al [9] in Brazil did not show correlation between vitamin D levels and FM, or association between pain intensity (regardless of FM diagnosis) and vitamin D deficiency or insufficiency.

The present study did not show statistically significant correlation between vitamin D concentrations and FM, and this outcome can be associated with the exposure of most patients and controls to sunlight for more than $30 \mathrm{~min}$ a day. However, patients presenting higher FIQ scores recorded lower vitamin D levels - this parameter was not evaluated in the Brazilian study and it may be associated with lower exposure to sun due to limited functional capacity. It is also likely that the most symptomatic individuals are more careful when it comes to being exposed to the sun (by avoiding it), or that they use sunscreen more often than healthy individuals, although photoprotection was not evaluated in the current study. Other studies did not present statistically significant correlation between disease impact and vitamin D concentrations [24, 25].

Intervention studies focused on vitamin D supplementation have criticized methodology aspects such as small sample size, population heterogeneity and study design, few doubleblind and placebo-controlled trials. The literature review conducted by Straube et al [26] has analyzed therapeutic studies that together have assessed 733 patients; one-third of these studies was based on randomized double-blind trials and only $22(10 \%)$ of them showed significant pain improvement due 
Table 2. Comparison Between Vitamin D Concentrations Based on Variables Investigated in Fibromyalgia Patients

\begin{tabular}{|c|c|c|c|}
\hline \multirow{2}{*}{ Variables } & \multirow{2}{*}{$\mathbf{n}$} & \multicolumn{2}{|c|}{ Vitamin D concentration } \\
\hline & & Mean \pm standard deviation & P value \\
\hline Skin phototype & & & $0.889^{\mathrm{a}}$ \\
\hline II & 9 & $34.9 \pm 13.0$ & \\
\hline III & 21 & $34.2 \pm 10.1$ & \\
\hline $\mathrm{V}$ & 5 & $30.3 \pm 12.5$ & \\
\hline Smoking & & & $0.070^{\mathrm{b}}$ \\
\hline Yes & 7 & $40.2 \pm 10.5$ & \\
\hline No & 36 & $33.7 \pm 12.1$ & \\
\hline Alcohol consumption & & & $0.431^{b}$ \\
\hline Yes & 26 & $39.5 \pm 12.6$ & \\
\hline No & 15 & $27.1 \pm 6.4$ & \\
\hline Indoors $^{\mathrm{d}}$ & & & $0.022^{b}$ \\
\hline Yes & 27 & $31.9 \pm 11.0$ & \\
\hline No & 14 & $40.9 \pm 12.8$ & \\
\hline Exercising & & & $0.516^{\mathrm{b}}$ \\
\hline Yes & 15 & $33.4 \pm 12.3$ & \\
\hline No & 28 & $35.5 \pm 12.0$ & \\
\hline
\end{tabular}

${ }^{a}$ Kruskal-Wallis test. ${ }^{b}$ Mann-Whitney test. 'Exposure for at least half an hour a day, or at least $3-4 \mathrm{~h}$ a week. ${ }^{d}$ Staying indoors most of the days.

Table 3. Comparison of Analyzed Variables Between Fibromyalgia Patients and Controls

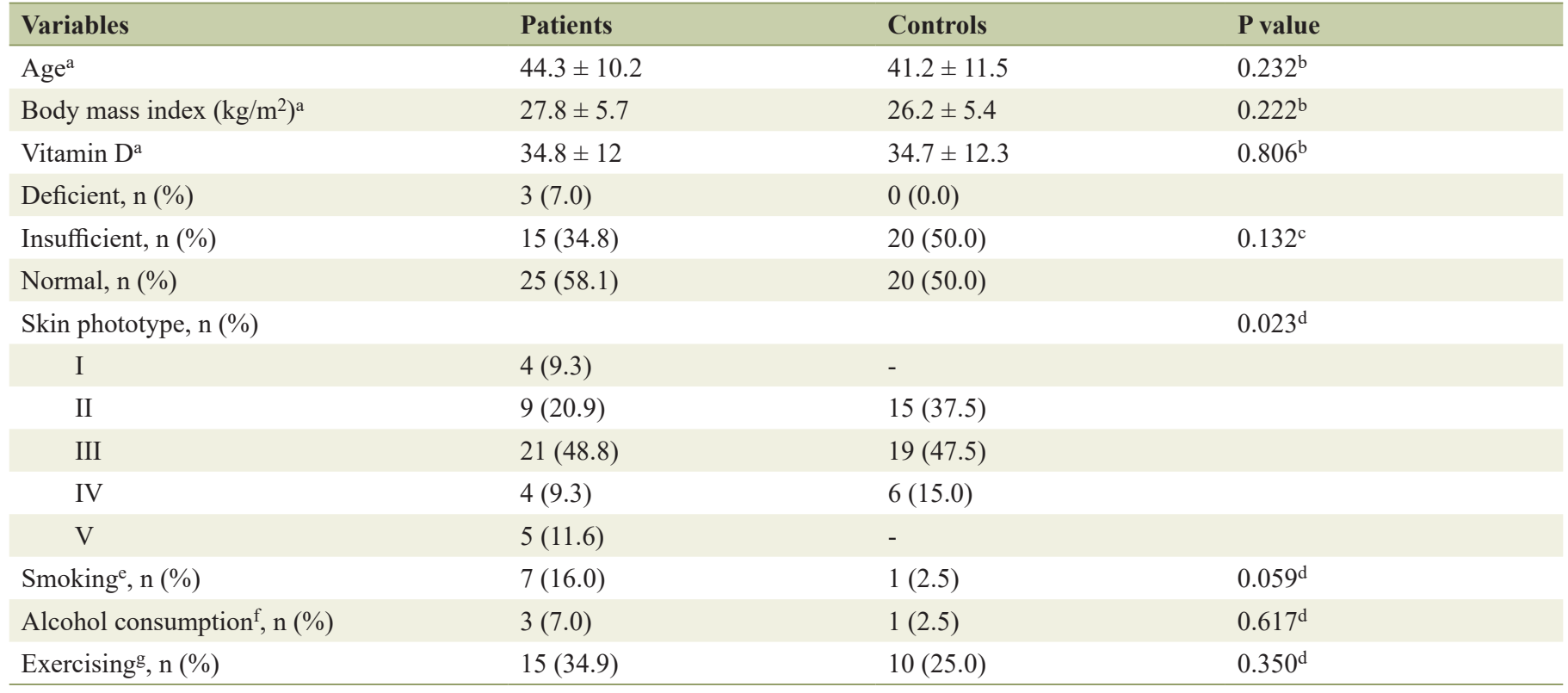

${ }^{a}$ Mean \pm standard deviation. ${ }^{b}$ Mann-Whitney test. ${ }^{c}$ Chi-square test. ${ }^{\mathrm{d}}$ Fisher's exact test. ${ }^{e}$ Current smokers. ${ }^{\mathrm{f} D a i l y}$ or sporadic alcohol drinker. ${ }^{\mathrm{g}}$ Regular exercisers. 
Table 4. Correlation Between Clinical and Laboratory Variables Investigated in the Control Group

\begin{tabular}{lll}
\hline Variables & \multicolumn{2}{c}{ Vitamin D concentration } \\
\hline Age & Spearman's correlation coefficient & P value \\
\hline FIQ & -0.094 & 0.398 \\
VAS & -0.360 & 0.018 \\
Body mass index $\left(\mathrm{kg} / \mathrm{m}^{2}\right)$ & -0.221 & 0.155 \\
Calcium & -0.169 & 0.126 \\
Albumin $(\mathrm{g} / \mathrm{dL})$ & 0.139 & 0.376 \\
Phosphorus (mg/dL) & 0.070 & 0.658 \\
Parathyroid hormone (Unit) & -0.065 & 0.678 \\
\hline
\end{tabular}

FIQ: fibromyalgia impact questionnaire; VAS: visual analogue scale.

to vitamin D supplementation. A recent study was conducted with 74 FM and hypovitaminosis D (vitamin D concentrations lower than $30 \mathrm{ng} / \mathrm{mL}$ ) patients who were randomized into two groups: one group was treated with $25 \mathrm{mg}$ of trazodone associated with 50,000 IU of cholecalciferol, whereas the other group received the same dose of trazodone associated with placebo. Pain-related indices, such as the generalized pain index and quality-of-life scale (SF-36), recorded the most noticeable improvement in patients subjected to the trazodone/vitamin D therapy [27].

Hypothetically, vitamin D can contribute to FM symptoms by affecting neuronal excitability, activating signal transduction systems, inhibiting COX-2 expression and by degrading prostaglandin. In addition, vitamin D lowers tumor necrosis factor (TNF) alpha levels and inhibits the synthesis of nitric oxide, which acts as an important neurotransmitter in central sensitization processes. One can also argue about whether vitamin D deficiency does not result from negative effects on patients' diet, in addition to the low exposure to sun due to mood changes often seen in FM patients [21]. Although most FM patients investigated in the current study presented sufficient vitamin D concentrations, vitamin D deficiency was found only in the FM group. This outcome can be associated with their low exposure to sun and to the fact the FM group was less physically active.

Despite the high incidence of sunlight in Brazil for most of the year, vitamin D deficiency persists. According to a study conducted in Recife (PE) [28], individuals exposed to the highest solar index presented the highest skin phototype categories, and it suggested that their skin got tanned due to exposure to sunlight. Most patients assessed in the current study presented skin phototype III; the lowest vitamin D concentrations were recorded for skin phototype $\mathrm{V}$, but mean vitamin $\mathrm{D}$ values were similar between phototypes - there was no statistically significant difference between them. The assessment of skin areas exposed to the sun was a potential limitation of the current study, although most individuals reported exposure time beyond that required to enable the photoconversion of the recommended amounts of vitamin D in the skin, namely, at least 30 min a day [29]. In addition, serum vitamin D concentrations were not measured in the spring, when vitamin D stocks in the liver had already been used, a fact that limits the effect of seasonal fluctuations on vitamin D biosynthesis [30].

There was no statistically significant association among BMI, alcohol consumption, smoking and exercising. Despite the findings in the current study, the association between obesity and FM was evaluated in some studies, whose results showed variation of $20-30 \%$ in overweight and $40-50 \%$ in obesity in FM patients $[31,32]$. Aspects such as the genetic profile of the investigated population, use of antidepressant drugs and eating habits can explain such divergent results.

\section{Conclusion}

In conclusion, FM patients did not show lower vitamin D concentrations, or higher frequency of vitamin D insufficiency/ deficiency, than healthy controls living in the same region. However, they presented slight negative correlation between serum vitamin D levels and the stronger impact of FM-associated symptoms.

\section{Acknowledgments}

None to declare.

\section{Financial Disclosure}

None to declare.

\section{Conflict of Interest}

None to declare.

\section{Informed Consent}

Individuals who agreed to participate in the research have signed the informed consent form. 


\section{Author Contributions}

Susyane designed the study, performed the experiments and wrote the manuscript; Fabiola and Roseli designed the study and analyzed the data. Myllena reviewed the final version of the manuscript.

\section{Data Availability}

Any inquiries regarding supporting data availability of this study should be directed to the corresponding author.

\section{References}

1. Wolfe F, Clauw DJ, Fitzcharles MA, Goldenberg DL, Hauser W, Katz RS, Mease P, et al. Fibromyalgia criteria and severity scales for clinical and epidemiological studies: a modification of the ACR Preliminary Diagnostic Criteria for Fibromyalgia. J Rheumatol. 2011;38(6):1113-1122.

2. Wolfe F, Clauw DJ, Fitzcharles MA, Goldenberg DL, Katz RS, Mease P, Russell AS, et al. The American College of Rheumatology preliminary diagnostic criteria for fibromyalgia and measurement of symptom severity. Arthritis Care Res (Hoboken). 2010;62(5):600-610.

3. Senna ER, De Barros AL, Silva EO, Costa IF, Pereira LV, Ciconelli RM, Ferraz MB. Prevalence of rheumatic diseases in Brazil: a study using the COPCORD approach. J Rheumatol. 2004;31(3):594-597.

4. Smith HS, Harris R, Clauw D. Fibromyalgia: an afferent processing disorder leading to a complex pain generalized syndrome. Pain Physician. 2011;14(2):E217-245.

5. Olama SM, Senna MK, Elarman MM, Elhawary G. Serum vitamin $\mathrm{D}$ level and bone mineral density in premenopausal Egyptian women with fibromyalgia. Rheumatol Int. 2013;33(1):185-192.

6. Malabanan AO, Turner AK, Holick MF. Severe generalized bone pain and osteoporosis in a premenopausal black female: effect of Vitamin D replacement. J Clin Densitom. 1998;1:201-204.

7. Karras S, Rapti E, Matsoukas S, Kotsa K. Vitamin D in fibromyalgia: a causative or confounding biological interplay? Nutrients. 2016;8(6).

8. Jesus CA, Feder D, Peres MF. The role of vitamin D in pathophysiology and treatment of fibromyalgia. Curr Pain Headache Rep. 2013;17(8):355.

9. de Rezende Pena C, Grillo LP, das Chagas Medeiros MM. Evaluation of 25-hydroxyvitamin D serum levels in patients with fibromyalgia. J Clin Rheumatol. 2010;16(8):365-369.

10. de Carvalho JF, da Rocha Araujo FAG, da Mota LMA, Aires RB, de Araujo RP. Vitamin D Supplementation Seems to Improve Fibromyalgia Symptoms: Preliminary Results. Isr Med Assoc J. 2018;20(6):379-381.

11. IBGE. Departamento de Cartografia. Mapa de Clima do Brasil. 2002. https://www.ibge.gov.br/geociencias/ informacoes-ambientais/climatologia/15817-clima. html? $=\& \mathrm{t}=$ o-que-e. Accessed on November 27th, 2018.

12. UFRGS. Lista de Coordenadas dos Municipios no Brasil. 2018. http://astro.if.ufrgs.br/br.htm. Accessed on November 26th, 2018.

13. Marques AP, Santos AMB, Assumpcao A, Matsutani LA, Lage LV, Pereira CAB. Validation of the Brazilian version of the fibromyalgia Impact questionnaire (FIQ). Revista Brasileira de Reumatologia 2006; 46:24-31.

14. Arija V, Perez Rodrigo C, Martinez de Vitoria E, Ortega RM, Serra-Majem L, Ribas L, Aranceta J. Dietary intake and anthropometric reference values in population studies. Nutr Hosp. 2015;31(Suppl 3):157-167.

15. World Health Organization. Physical status: the use and interpretation of anthropometry. Report of a WHO Expert Committee. World Health Organization. https://www. who.int/childgrowth/publications/physical_status/en/. Online First: November 27, 2018.

16. Fitzpatrick TB. The validity and practicality of sunreactive skin types I through VI. Arch Dermatol. 1988;124(6):869-871.

17. Roth HJ, Schmidt-Gayk H, Weber H, Niederau C. Accuracy and clinical implications of seven 25-hydroxyvitamin D methods compared with liquid chromatography-tandem mass spectrometry as a reference. Ann Clin Biochem. 2008;45(Pt 2):153-159.

18. Holick MF, Binkley NC, Bischoff-Ferrari HA, Gordon CM, Hanley DA, Heaney RP, Murad MH, et al. Evaluation, treatment, and prevention of vitamin D deficiency: an Endocrine Society clinical practice guideline. J Clin Endocrinol Metab. 2011;96(7):1911-1930.

19. von Elm E, Altman DG, Egger M, Pocock SJ, Gotzsche PC, Vandenbroucke JP, Initiative S. The Strengthening the Reporting of Observational Studies in Epidemiology (STROBE) statement: guidelines for reporting observational studies. J Clin Epidemiol. 2008;61(4):344-349.

20. Armstrong DJ, Meenagh GK, Bickle I, Lee AS, Curran ES, Finch MB. Vitamin D deficiency is associated with anxiety and depression in fibromyalgia. Clin Rheumatol. 2007;26(4):551-554.

21. Okyay R, Kocyigit BF, Gursoy S. Vitamin D levels in women with fibromyalgia and relationship between pain, tender point count and disease activity. Acta Med Mediterr. 2016;32:243-247.

22. Huisman AM, White KP, Algra A, Harth M, Vieth R, Jacobs JW, Bijlsma JW, et al. Vitamin D levels in women with systemic lupus erythematosus and fibromyalgia. J Rheumatol. 2001;28(11):2535-2539.

23. Tandeter H, Grynbaum M, Zuili I, Shany S, Shvartzman P. Serum 25-OH vitamin D levels in patients with fibromyalgia. Isr Med Assoc J. 2009;11(6):339-342.

24. Mateos F, Valero C, Olmos JM, Casanueva B, Castillo J, Martinez J, Hernandez JL, et al. Bone mass and vitamin $\mathrm{D}$ levels in women with a diagnosis of fibromyalgia. Osteoporos Int. 2014;25(2):525-533.

25. Maafi AA, Ghavidel-Parsa B, Haghdoost A, Aarabi Y, Hajiabbasi A, Shenavar Masooleh I, Zayeni H, et al. Serum Vitamin D Status in Iranian Fibromyalgia Patients: according to the Symptom Severity and Illness Invalidation. Korean J Pain. 2016;29(3):172-178. 
26. Straube S, Derry S, Straube C, Moore RA. Vitamin D for the treatment of chronic painful conditions in adults. Cochrane Database Syst Rev. 2015;5:CD007771.

27. Mirzaei A, Zabihiyeganeh M, Jahed SA, Khiabani E, Nojomi M, Ghaffari S. Effects of vitamin D optimization on quality of life of patients with fibromyalgia: A randomized controlled trial. Med J Islam Repub Iran. 2018;32:29.

28. Correia A, Azevedo Mdo S, Gondim F, Bandeira F. Ethnic aspects of vitamin D deficiency. Arq Bras Endocrinol Metabol. 2014;58(5):540-544.

29. Fraser DR. Vitamin D. Lancet. 1995;345(8942):104-107.
30. Souza Mario Bueno L, Rosset C, Aguiar E, Pereira Fde S, Izetti Ribeiro P, Scalco R, Matzenbacher Bittar C, et al. Vitamin D status and VDR genotype in NF1 patients: a case-control study from Southern Brazil. Int J Endocrinol. 2015;2015:402838.

31. Gota CE, Kaouk S, Wilke WS. Fibromyalgia and Obesity: The association between body mass index and disability, depression, history of abuse, medications, and comorbidities. J Clin Rheumatol. 2015;21(6):289-295.

32. Okifuji A, Hare BD. The association between chronic pain and obesity. J Pain Res. 2015;8:399-408. 